*Mestre em Bioética pela Universidade Vale do Sapucaí (Univás)

E-mail: advbaganha@gmail.

com

**Doutor em Direito Público pela Universidade do Vale do Rio dos Sinos (Unisinos)

E-mail: rafaelsimioni@univas. edu.br

\section{COMÉRCIO JUSTO E BIOÉTICA: A LEGITIMIDADE DE REGIMES JURÍDICOS PRIVADOS}

\author{
FAIR TRADE AND BIOETHICS: THE LEGITIMACY OF PRIVATE \\ LEGAL SCHEMES
}

\section{José Ricardo dos Santos Baganha* Rafael Lazzarotto Simioni**}

Como citar: BAGANHA, José Ricardo dos Santos; SIMIONI, Rafael Lazzarotto. Comércio justo e bioética: a legitimidade de regimes jurídicos privados. Scientia Iuris, Londrina, v. 25, n. 2, p. $168-186$, jul. 2021. DOI: $10.5433 / 21788189.2021 \mathrm{v} 25 \mathrm{n} 2 \mathrm{p} 168$. ISSN: $2178-8189$.

Resumo: O sistema do Comércio Justo - Fair Trade - é uma estrutura de comércio em rede, certificada por boas práticas de sustentabilidade cujos conceitos e princípios dialogam pela inserção de regramentos éticos nos espectros sociais, econômicos e ambientais, características contra-hegemônicas se comparadas com os pressupostos do capitalismo liberal. Este modelo negocial inovador, por ser uma experiência à partir do Hemisfério Norte, reacende a questão da colonialidade e da legitimidade das normas definidas no âmbito da rede. Esta pesquisa estabelece uma reflexão sobre este regime jurídico de comércio em rede, que regulamenta as atividades de todos os atores que se relacionam dentro do movimento do Comércio Justo, buscando compreender como uma proposta se legitima frente aos mais diferentes países, culturas e sistemas jurídicos e possibilita uma articulação de atividades, no propósito discursivo de desenvolvimento de agricultores vulneráveis e suas comunidades. A metodologia utilizada foi analítica e a técnica de revisão literária. Como resultado, obteve-se a percepção de que as regras adotadas priorizam uma abordagem sistêmica de um projeto, no qual a relação de compra e venda e nem mesmo o lucro são tidos como um fim em si mesmo, como objetivo principal.

Palavras-chave: cafeicultura, cooperativismo, certificação, regimes jurídicos privados, equidade e justiça. 


\begin{abstract}
The Fair-Trade system is a network commerce structure, certified by good sustainability practices whose concepts and principles dialogue by the insertion of ethical rules in the social, economic and environmental spectrums, counter-hegemonic characteristics if compared to the assumptions of liberal capitalism. This innovative business model, as an experience from the Northern Hemisphere, rekindles the issue of coloniality and the legitimacy of the norms defined within the network. This research establishes a reflection on this legal regime of networked commerce, which regulates the activities of all actors that connect within the Fair-Trade movement, seeking to understand how a proposal is legitimized in front of the most different countries, cultures and legal systems and enables an articulation of activities, in the discursive purpose of development of vulnerable farmers and their communities. The methodology used was analytical and literature review. As a result, this paper perceives that the rules adopted prioritize a systemic approach to a project, in which the buying and selling relationship and not even profit is taken as an end in itself, as the main objective.
\end{abstract}

Keywords: coffee, cooperativism, certification, private legal regimes, equity and justice. 


\section{INTRODUÇÃO}

O modelo adotado pela rede de Comércio Justo tem se apresentado como uma proposta inovadora e alternativa ao modelo capitalista de comércio vigente. Surgido entre as décadas de 1940 e 1950 de ações voluntárias e altruístas de entidades religiosas e filantrópicas transnacionais, como reação às crises humanitárias decorrentes da crescente desigualdade e acentuação de pobreza nos países do Sul mundial, trazia em seu âmago a convicção de que o pensamento liberal falhou e que, portanto, iniciativas individuais não promoviam naturalmente o bem e o interesse coletivo.

Em sua trajetória as ações do movimento evoluíram da solidariedade para o mercado e suas estratégias rumaram para iniciativas desenvolvimentistas, contrárias à lógica do comércio internacional globalizado, notadamente no combate à racionalidade econômica dominante, cuja base lógica estrutural apropriou-se dos pensamentos, objetivos e ações das demais racionalidades, tornando tudo e o todo, produto em razão do lucro.

Atualmente definido como uma proposta de estabelecimento de relações comerciais baseadas no diálogo, transparência e respeito, com objetivo de obter o sentido mais próximo de equidade entre os atores no comércio internacional, promovendo melhoria nas relações sociais, desenvolvimento sustentável e proteção dos direitos dos pequenos produtores e trabalhadores, o Comércio Justo ao menos no plano conceitual, alinha-se aos valores e princípios da Bioética Global, voltada para a construção de uma nova forma de produção dos saberes, na preservação de toda forma de vida no planeta.

Com a Declaração Universal sobre Bioética e Direitos Humanos da Unesco (Organização das Nações Unidas para a Educação, a Ciência e a Cultura), o campo de atuação da Bioética foi ampliado para o âmbito das ciências sociais, penetrando no universo do conhecimento voltado para a equidade e a justiça social, buscando a correção das assimetrias existentes e a equalização de forças globais. Com o escopo de promover o desenvolvimento de ações urgentes e estratégicas, norteando uma visão política voltada para o respeito à pluralidade, dignidade e direitos humanos universais.

Entretanto, o conceito do Comércio Justo vem definido a partir de uma experiência do Hemisfério Norte para o Hemisfério Sul, o que pode reacender, dentre outras, a questão de uma nova estrutura de exercício de colonialidade e da baixa legitimidade das normas definidas no âmbito da rede.

Nessa perspectiva, objetiva-se estabelecer uma reflexão crítica sobre a relação entre regimes jurídicos privados como o Fair Trade e a legitimidade destas normas à luz da bioética global. Para tanto, parte-se de um breve histórico do comércio justo para relacionar com os principais preceitos da bioética global. Em um segundo momento, a pesquisa analisa a situação do pequeno cafeicultor do Sul de Minas Gerais e a crise do café, estabelecendo uma comparação entre os princípios contratuais clássicos e os princípios contratuais definidos nos regimes contratuais privados do Comércio Justo. No final, a pesquisa analisa as regras do Comércio Justo como instrumento de desenvolvimento econômico e social.

Para serem alcançados estes resultados, essa pesquisa utiliza o método analítico e a técnica de revisão literária. Como referencial teórico, esta investigação utiliza tanto os referenciais Schramm, Pessini e Garrafa bem como a noção de regimes jurídicos privados desenvolvidos no âmbito da teoria dos sistemas de Gunther Theubner. Esse referencial teórico torna possível o diálogo entre Bioética e Direito, por meio do qual, esta pesquisa coloca a questão da legitimidade destes regimes jurídicos privados, pensados em uma perspectiva europeia, para a realidade da região do Sul de Minas Gerais, cuja história é marcada pela inscrição de uma cultura colonial. 


\section{BREVE HISTÓRICO DO COMÉRCIO JUSTO}

Nas décadas de 40 e 50 surgiram as primeiras iniciativas de movimentos sociais nos Estados Unidos da América (EUA) e Europa, no propósito de aproximar e desenvolver territórios em desvantagem política e econômica do Sul ao comércio do Norte (MASCARENHAS, 2007, p. 2).

Inicialmente as redes e círculos de integração destas instituições promoviam feiras e bazares que evoluíram para um conjunto de lojas temáticas (Word Shops), iniciativas de comércio alternativo que se organizaram por meio da associação de comércio alternativo ATO (Alternative Trade Organizations) (SCHNEIDER, 2012, p. 21-22).

Os projetos políticos de reconstrução e desenvolvimento no pós segunda guerra mundial, movimentos como da solidariedade internacional comércio para o desenvolvimento (developmental trade), notadamente após a Conferência da ONU de 1964, onde o lema "comércio não ajuda" (trade, not aid) marcou o início de um novo modo de agir nas relações Norte-Sul, posicionando o comércio como uma ferramenta para o desenvolvimento (MASCARENHAS, 2007, p. 45-46).

No final da década de 1980 e início de 1990 o Comércio Justo encampa valores de desenvolvimento sustentável por uma consciência global de preservação do meio ambiente, da proteção da dignidade humana e a necessidade de combater as desigualdades sociais e econômicas entre o eixo Norte-Sul. A estruturação de parcerias comerciais se aperfeiçoou por meio de uma complexa unificação e regulamentação das certificadoras pela FLO - Fairtrade Labelling Organizations International e tornou toda rede de comercialização auditada por este selo, desde o produtor, importador, torrefador, até o produto apresentado ao consumidor final.

Em outubro de 2001 os grupos FLO, IFAT, NEWS e EFTA (Associação Europeia de Comércio Justo) criaram uma organização guarda-chuva com objetivo de convergir os principais atores do Comércio Justo na Europa - FINE (WILKINSON, 2007, p. 221) e em 2002 surge a definição de Comércio Justo, a qual foi revista e ratificada em 25 de setembro de 2018, com a redação "o Comércio Justo é uma parceria comercial baseada no diálogo, na transparência e no respeito que busca maior equidade no comércio internacional. Contribui para o desenvolvimento sustentável, oferecendo melhores condições comerciais e garantindo os direitos dos produtores e trabalhadores marginalizados - especialmente no sul" (FLO, 2018).

Surgem a World Fair Trade Organization (WFTO) (SCHNEIDER, 2012, p. 45) e a Coordenadora Latino-Americano e do Caribe de Pequenos Produtores e Trabalhadores do Comércio Justo, cuja missão de "representar e promover os interesses, capacitação e desenvolvimento de seus membros e de suas comunidades" para o crescimento do movimento (CLAC, 2019).

Em 2015 a Associação Brasileira de Comércio Justo, atual Fair Trade Brasil, também se instalou no país tendo como função o gerenciamento do uso da marca Fairtrade, bem como a divulgação e prospecção do movimento perante o mercado consumidor (BARONE, 2017, p. 92).

Segundo Abrahamsen (2004, p. 1455) a forma de atuação do C.J que oferece aos países receptores a "propriedade" de seus programas desenvolvimentistas, com acesso a processos de organização, conhecimentos técnicos e científicos, apoio de estruturação e fomento, são como uma forma de poder liberal avançada, onde as parcerias não trabalham primariamente, com dominação e imposição direta, mas através de promessas de incorporação e inclusão.

Para Grewal (2008, p. 92) a diferença entre as redes de Comércio Justo e as de Comércio Internacional tradicionais está na cooperação, no foco para formação de parcerias duradouras de negócios, com eliminação de atravessadores, constante trabalho de manutenção das redes, fortalecimento dos conceitos e valores do sistema perante o mercado consumidor e sociedade.

Os produtores são organizados por cooperativas ou associações, que devem adotar sistema democrático em seus processos decisórios e ter capacidade para exportação. As certificadoras fazem o processo de padronização de boas práticas, de modo a trazer credibilidade e garantia da 
origem e identificação do comércio justo, o que agrega valor ao produto por suas características sustentáveis, de modo a justificar uma predileção do consumidor consciente pelo produto com um maior preço final na prateleira (PEDINI, 2014, p. 466).

Uma parte do valor agregado aos produtores retorna aos produtores por meio de acesso a contratos de pré-financiamentos, garantia de preço mínimo e prêmio do Comércio Justo, este último, com finalidade de promover projetos sociais nas comunidades onde residem os produtores, trazendo desenvolvimento sustentável de territórios de produtores (McEWAN; BEK, 2009, p. 257).

No entanto, a proposta do comércio justo se circunscreve de elementos desafiadores, como a presunção de que o mercado proveria meios para custear as melhorias sociais e ambientais aos pequenos produtores, absorvendo os seus custos maiores, cujo valor agregado estão estabelecidos em fatores intrínsecos, de uma crença e engajamento a uma causa (WILKINSON, 2007, p. 230).

Essa crença encampa a ideia de justiça como valor agregado ao produto cuja produção observou melhores condições de trabalho, a promoção de desenvolvimento social e humano, identificada pelo consumidor através do selo da certificação (RIOS; FINKELSTEIN; LANDA, 2014, p. 172).

Trata-se de uma relação de confiança onde estes atributos estão amparados na existência do selo, sendo este o símbolo que remete os valores intrínsecos do produto, entre comerciante e consumidor (CASTALDO et al, 2009, p. 10).

À partir destes levantamentos bibliográficos surge a necessidade de compreender como o Comércio Justo legitima seu projeto discursivo em suas regras de certificação que permeia toda rede de comércio e sua segmentação.

\section{BREVE NOÇÃO HISTÓRICA DA BIOÉTICA}

A bioética hodiernamente conhecida teve como marco a publicação pelo norte-americano Van Renssealaer Potter, bioquímico, professor e pesquisador na área da oncologia, no qual elaborou o neologismo bioethics em dois artigos, sendo o primeiro "Bioethics, science of survival", publicado em Persp Biol Med (1970) e em sequência em sua célebre e mais conhecida obra "Bioethics: bridge to the future" (1971) (PESSINI, 2013, p. 10).

Em seu trabalho Potter idealiza um pensamento ético aplicado, um novo propósito do saber científico, voltado para sobrevivência e perenidade humana no globo, pressupondo uma nova ética para comunidade científica que combinasse humildade, responsabilidade e competência, cuja abordagem e enfoque interdisciplinar e intercultural, pudessem redefinir, redirecionar e potencializar o rumo da humanidade (PESSINI, 2013, p. 10).

No entanto, em 1927 o Alemão Fritz Jahr, natural de Halle na Alemanha, já havia criado a palavra Bio-Ethik, com o intuito de propor uma espécie de responsabilidade moral humana por respeito à todas as formas de vida no planeta, à semelhança e sentido com que Kant propôs seu imperativo categórico do agir humano. A proposta de Jahr expandiu o objeto e abrangência para todas as formas de vida existentes no globo, não por sua utilidade, mas por seu valor intrínseco (PESSINI, 2013, p. 15).

O primeiro título de Potter "Bioética, ciência da sobrevivência" estabelece a dimensão da proposta que nortearia o exercício da produção e do uso do conhecimento, que se desenvolveria em amplitude global equalizando as diferentes moralidades das relações humanas com o ambiente natural (SCHRAMM, 2008, p. 19).

A "ciência da sobrevivência" se tornou uma "ponte para o futuro" no livro de $1971 \mathrm{em}$ que o autor especifica que a "ponte" seria de fato uma metáfora do "diálogo" entre Ciência e Ética, e cujas condições de possibilidade seriam dadas por uma forma de saber consciente de seus limites e também de suas responsabilidades (SCHRAMM, 2011, p. 303). 
Em 1998, durante o Quarto Congresso Mundial de Bioética no Japão, em Tóquio, a Bioética defendida por Potter foi reconduzida à cena principal do evento, cujo nome foi intitulado "Bioética Global", cujos artigos conduziram as ideias de expansão para o campo de estudo e ação, pontuando agora valores inerentes aos direitos humanos como qualidade de vida, proibição de discriminação como racismo, gênero, religião, segurança alimentar e, ainda, revisitando a preocupação para preservação da biodiversidade, o desenvolvimento sustentável (escassez de recursos naturais) dentre outros (GARRAFA, 2005, p. 129).

Em Outubro de 2005, a Conferência Geral da UNESCO adotou por aclamação a Declaração Universal sobre Bioética e Direitos Humanos, de modo que pela primeira vez na história da bioética, os Estados-membros comprometeram-se, e à comunidade internacional, a respeitar e aplicar os princípios fundamentais da bioética condensados num texto único, que veio tratar das questões éticas suscitadas pela medicina, ciências da vida e tecnologias associadas na sua aplicação aos seres humanos (UNESCO, 2005).

Assim, a Declaração ao incorporar os princípios que enuncia nas regras que norteiam o respeito pela dignidade humana, pelos direitos humanos e pelas liberdades fundamentais, consagrou a bioética entre os direitos humanos internacionais e garantiu o respeito pela vida dos seres humanos, reconhecendo a interligação que existe entre ética e direitos humanos no domínio específico da bioética.

\section{O PEQUENO CAFEICULTOR DE MONTANHA DO SUL DE MINAS E A CRISE DO CAFÉ}

O estado de Minas Gerais é o maior estado produtor de café do Brasil, responde por cerca de $50 \%$ da produção nacional, sendo $2 / 3$ da produção total de café Arábica. Devido à sua vasta extensão territorial, essa produção se realizada em diferentes características edafoclimáticas, geograficamente identificadas entre regiões a Zona da Mata, Sul, Cerrado e Chapada de Minas. A região do Sul de Minas (assim como a Zona da Mata) são denominadas produtoras de café de montanha, devido ao relevo muito acidentado (RUFINO; SILVEIRA; RIBEIRO JUNIOR, 2010, p. 9).

Por sua vez, o café de Montanha é responsável por cerca de $70 \%$ da produção de café de Minas Gerais. Em um universo de mais de 220 municípios produtores, constituem-se de elevada densidade do trabalho humano no cultivo e manejo, haja vista a impossibilidade de mecanização pela topografia acidentada do terreno.

$\mathrm{Na}$ região de Montanha do Sul de Minas Gerais, os produtores possuem entre 3 e 20 hectares de lavoura de café em média, a produção de café é predominantemente familiar em que parentes diretos realizam a maior parte das operações de manejo da lavoura, sendo que trabalhadores externos geralmente são contratados apenas para atividades de colheita e, eventualmente, na capina e adubação do cafezal (RUFINO; SILVEIRA; RIBEIRO JUNIOR, 2010, p. 30).

Semelhante situação de vulnerabilidade da agricultura praticada em regiões de montanha por pequenos produtores fomentou a adoção de políticas públicas de apoio para regiões consideradas como "Zonas com Desvantagens Geográficas e Naturais" no continente Europeu. A União Europeia por meio do Fundo Europeu de Desenvolvimento Regional (FEDER) protege os produtores vulneráveis, por meio da correção dos desequilíbrios regionais, buscando modernização e diversificação das estruturas econômicas (RUFINO; SILVEIRA; RIBEIRO JUNIOR, 2010, p. $10)$.

Trata-se, portanto, de uma condição de vulnerabilidade que assola diversas regiões do mundo de pequenos agricultores em decorrência de fatores naturais, sociais e mercadológicos.

O setor cafeeiro mundial entre as décadas de 1960 e 1980 era regulamentado por Acordos 
Internacionais do Café (AIC), nos quais países produtores se articulavam para intervir e assegurar preços em patamar mais elevado para garantir um percentual maior no preço final do produto aos produtores. Com a abertura de mercado e a globalização o controle de preços deixou o sistema de regulação dos acordos internacionais devido à pressão do neo-liberalismo exercido sobre os países produtores que, tal qual o Brasil, extinguiram seus órgãos internos (BARONE, 2017, p. 25) para permitir que o mercado o fizesse.

Essa mudança no mercado do café é concomitante ao processo de globalização que propalava progresso e desenvolvimento para os cidadãos dos países em desenvolvimento, a esperança de um mundo mais justo e equânime com a abertura comercial e das barreiras alfandegárias. No entanto, a abertura passou o controle de preços dos países produtores para as grandes empresas exportadoras e processadoras do produto e, com isso, os países do Sul - América Latina e Caribe - sofreram acentuado impacto de suas condições devido a uma desaceleração nos preços globais de commodities (WORD BANK, 2018).

Segundo a Organização Internacional do Café, OIC, a maioria entre 25 milhões de famílias de pequenos cafeicultores no mundo não consegue sequer cobrir seus custos de produção e vivem um processo de empobrecimento que está destruindo o tecido social nas áreas rurais de mais de 40 países da África, Ásia e América Latina.

Em alguns países, os produtores que insistem no cultivo do café não poderão pagar pelo cuidado adequado de suas propriedades e lavouras, o que leva ao inadequado manejo da produção, o que afeta a qualidade e priva os consumidores da diversidade que eles desfrutam hoje em dia. A adaptação e mitigação dos efeitos da mudança climática são outros encargos que recaem sobre os ombros dos produtores. E frente a esta realidade o Segundo Fórum de Países Produtores de Café, realizado na cidade de Campinas, Brasil, aos dias 10 e 11 de julho de 2019, identificou como principais desafios do setor a sustentabilidade econômica, ambiental e social, bem como a necessidade de interação e coordenação estratégica entre os agentes da cadeia produtiva (DECLARAÇÃO..., 2019).

\section{PRINCÍPIOS CONTRATUAIS}

Os princípios de direito contratual atualmente vigente em nosso sistema jurídico, dividemse entre tradicionais e pós-modernos, e assim são chamados por estarem diretamente ligados às conjecturas do tempo em que foram concebidos.

Durante o século XVIII até o início do século XX, os ideais clássicos da liberdade e igualdade, que inspiraram o Código napoleônico Francês, atendiam aos anseios da burguesia vitoriosa na revolução de 1789, em seus vieses político, ideológico e econômico. Nesse período o contrato e sua força obrigacional visava garantir o acesso e a circulação de riqueza, a aquisição da propriedade expressava a verdadeira expressão de liberdade. A burguesia promove a aquisição de bens e terras das classes antigas, normalmente improdutivas (VENOSA, 2003, p. 365).

Posteriormente o Código Alemão traz a conceituação do negócio jurídico como um instituto geral do qual o contrato passa a ser uma categoria, surgindo assim os princípios clássicos contratuais que validam os negócios, tendo em observação, a autonomia da vontade das partes, o consensualismo e obrigatoriedade dos contratos. Esse sistema foi adotado pelo direito brasileiro no Código Civil de 1916 e perdurou por grande parte até o final do século XX.

A autonomia da vontade de contratar deste modelo, pressupõe a paridade e a igualdade entre contratantes na formulação de todas as cláusulas e condições negociais. Ainda vivo, este modelo constitui pilastra do direito privado, quando o 'cidadão' contrata com seus iguais, sendo o consenso a expressão máxima da igualdade de poder entre contratantes (VENOSA, 2003, p. 366).

Entretanto, na sociedade pós-moderna, a relação entre partes cede lugar para novas formas de contratação, e a economia de massa é praticada agora por atores do mercado globalizado, desde 
as microempresas até os grandes detentores do capital (VENOSA, 2003, p. 367). Nesse novo cenário o Estado passa a intervir normatizando os negócios jurídicos visando garantir interesses coletivos sobre os interesses individuais, equalizando o interesse das partes em relação aos interesses da sociedade.

Esse novo sistema é adotado pelo Código Civil de 2002, que mitiga o individualismo do antigo código para conceber o ideal de justiça social, incluindo entre os princípios tradicionais o princípio da supremacia da ordem pública, da revisão dos contratos, boa-fé e da função social. Todo esse esforço decorre das transformações que o mercado de consumo em massa promove no âmbito das relações humanas, já que a autonomia da vontade sofre relativismos e limitações, como na capacidade de escolha do uso de transporte público ou na contratação do seguro obrigatório veicular (PEREIRA, 2004), bem como de outros serviços públicos como luz, água e esgoto (DINIZ, 2003).

Assim, é que o conteúdo e cláusulas contratuais outrora definido pelas partes estão agora submetidas a limitações das cláusulas gerais que tratam da função social, da boa-fé objetiva e supremacia da ordem pública, ou seja, o princípio da autonomia da vontade se reduz a opção de estabelecer vínculo obrigacional, pois, o interesse geral da ordem pública e os bons costumes, constituem claros limites à liberdade de contratar (DINIZ, 2003).

Segundo Diniz (2003) o princípio do consensualismo tem no consenso um requisito subjetivo da formação contratual, onde o acordo de duas ou mais vontades devem estar isentas de vícios como erro, dolo, coação, lesão, estado de perigo, simulação e fraude, acerca da existência, natureza, objeto e cláusulas que compõem o contrato. Para Bulgarelli (2001) o consensualismo caracteriza-se pela ausência de qualquer solenidade na celebração dos contratos, bastando o simples consentimento, o simples acordo de vontades, e somente em caráter excepcional são exigidas algumas formalidades.

O pacta sunt servanda é princípio geral de Direito que remete à força obrigacional do contrato, em que se afirma que o 'contrato faz lei entre as partes'. As estipulações feitas no contrato deverão ser fielmente cumpridas, isto porque uma vez concluído livremente, constitui-se uma verdadeira norma de direito, sendo intangível, a menos que haja consenso em sua alteração ou ocorra escusa por caso fortuito ou força maior (DINIZ, 2003).

O princípio da revisão dos contratos ou da onerosidade excessiva aproxima-se de uma antítese ao princípio da obrigatoriedade, pois, permite aos contratantes recorrerem ao poder judiciário para pleitear a revisão, observando que as condições em que estavam durante a celebração do contrato tenham sido alteradas a ponto de tornar, a uma das partes, o cumprimento contratual excessivamente oneroso. Este princípio decorre da chamada cláusula "rebus sic stantibus".

Com a globalização da economia a empresa substitui o Estado na função de promover o desenvolvimento, o valor da propriedade é relativizado pela geração de riqueza e renda, as relações humanas são permeadas por estes novos valores, de modo que os negócios jurídicos de massa ganham status e relevante valor social (VENOSA, 2003, p. 368).

O contrato rígido entre particulares passa a ter valor em função social e ganha proteção do Estado que, antes era estático e agora interfere nas relações contratuais privadas, para proibir ou impor regras de interesse público (VENOSA, 2003, p. 369). Para Pereira (2004) o princípio da função social do contrato atua na limitação da autonomia da vontade individual em divergência com o interesse social que deva prevalecer.

O valor da função social do contrato é princípio moderno que se alinha com os princípios tradicionais atenuando-os quando conflitantes com os inafastáveis direitos metadindividuais jurídicos, sociais, econômicos e morais.

O princípio da boa-fé também é considerado um princípio geral por ser aplicado ao direito obrigacional de maneira a garantir que as partes assim atuem desde as tratativas iniciais, como bem na formação, execução, extinção nas relações contratuais. É, pois, norma pela qual se norteia 
o trabalho hermenêutico do operador do direito que está vinculado à intepretação das cláusulas escritas, observando que as partes deverão agir sempre com lealdade, honestidade e confiança recíprocas, esclarecendo a intenção, os fatos e o pactuado, procurando o equilíbrio nas prestações, evitando o enriquecimento indevido e ilícito (DINIZ, 2003).

De relevância ainda observar que a boa-fé se subdivide em objetiva e subjetiva. A subjetiva se refere à percepção do agente contratante, é considerada sob a ótica de sua real compreensão do seu ato, tendo em vista o grau de conhecimento que possui em um negócio. A objetiva leva em conta um padrão de conduta comum, de homem médio, padrões sociais de uma comunidade (VENOSA, 2003, p. 379).

A apresentação destes princípios contratuais constantes do ordenamento jurídico brasileiro se faz importante para o presente estudo na medida em que, apesar do esforço do anteparo jurídico apresentado, na prática os negócios entre desiguais que envolvem parcela vulnerável de atores, como os cafeicultores familiares de montanha, nenhuma proteção prática e efetiva os socorre da lógica no neo-liberalismo econômico, relegando-os ao isolamento, à falta de perspectivas de crescimento e desenvolvimento.

\section{A COMPRA E VENDA NO SISTEMA TRADICIONAL DO CAFÉ}

A compra e venda se define como contrato em que uma pessoa se obriga a transferir a outra o domínio de uma coisa, mediante pagamento de preço certo em dinheiro ou valor fiduciário equivalente (DINIZ, 2003, p. 171). Em síntese, são elementos essenciais a coisa (res), o acordo de vontade (consensus) e o preço (pretium).

A coisa deverá ter existência, ainda que potencial, deverá ser individualizada, disponível e transferível ao comprador. O consentimento deverá observar a capacidade dos contratantes para praticar atos da vida civil.

O preço deve ser oneroso, ajustado de forma séria, fixado com certeza. A fixação do preço como elemento essencial, pode ser creditada à terceiro, a tabelas de mercado, índices de indexação futuros e, quando não convencionada explicitamente, presume-se que acordaram à prática e habitualidade exercitada pelo vendedor. Porém, o negócio será nulo quando a fixação do preço ficar à mercê exclusiva de uma das partes (DINIZ, 2003, p. 171).

Não se pretende esgotar aqui as classificações, peculiaridades e estudos sobre o instituto da compra e venda, apenas conjecturar os elementos que compõem a espécie de negócio jurídico sob o qual incidem toda ordem principiológica exposta no item anterior e, assim, problematizar com o universo vivido pelos pequenos cafeicultores do Sul de Minas antes da inserção ao contexto das regras do Fair Trade.

Em síntese essa relação é permeada por uma assimetria de poder entre vendedor e comprador, ou seja, não existiam igualdade e paridade de partes no contrato, desconstituindo a presunção em que se sustenta o princípio clássico da autonomia da vontade.

O pequeno cafeicultor, individualmente isolado, exposto aos fatores de distanciamento geográfico, social e econômica, não possui força de negociação junto às empresas compradoras (atravessadores) que, por sua vez, atuam praticamente sem concorrência.

O preço da saca de café fixado pelas tabelas diárias vinculadas aos índices da Bolsa de Valores de Nova Yorque, com variáveis distantes e desconexas aos custos de produção do cafeicultor, como a lei da oferta e demanda, a própria qualidade do café, o clima e a especulação financeira, além do despreparo técnico relacionado à avaliação, classificação dos grãos e sua precificação, invariavelmente, retratam a vulnerabilidade dos pequenos produtores que simplesmente entregam suas produções sem uma efetiva e justa negociação de compra e venda.

Esta realidade frente aos princípios contratuais clássicos e modernos supra expostos, demonstra que neste modelo negocial de compra e venda de café realizados no sistema tradicional 
(spot), os esforços jurídicos não são suficientes para alcançar os fatores que fragilizam e tornam os cafeicultores vulneráveis, gerando assimetrias e perdas ao elo mais frágil da relação contratual, o pequeno cafeicultor.

\section{DOS PRINCÍPIOS CONTRATUAIS E A PRODUÇÃO JURÍDICA DO FAIR TRA- DE}

Assim, no âmbito deste trabalho consideramos os regramentos da FLO e WFTO que expressam a concordância e união de diversas ações nacionais de Comércio Justo e que se organizaram para fortalecer conceitos, valores, critérios e sedimentar a marca com credibilidade no mercado. Estes regramentos são adotados no universo das instituições certificadas no Sul de Minas Gerais em que estão participando os cafeicultores colaboradores desta pesquisa.

Segundo consta no sítio virtual do Comércio Justo (Fairtrade) os critérios são projetados com objetivo de combater a pobreza e capacitar produtores nos países mais pobres do mundo, envolvendo e obrigando produtores e comerciantes (FLO, 2019b). Estes padrões são definidos de acordo com o Código de Boas Práticas da ISEAL sobre definição padrões sociais e ambientais. Esse processo envolve ampla consulta com as partes interessadas (FLO, 2019a).

A Fairtrade International explica que a elaboração de um padrão pode surgir através de diversas iniciativas, pode surgir internamente, pode surgir por uma das partes interessadas (produtores, comerciantes, distribuidores), o que se dá pela uma solicitação de elaboração de um projeto padrão. Esse projeto padrão pode servir para desenvolver um novo padrão ou revisar um padrão existente. Qualquer projeto começa com a elaboração de uma tarefa de projeto, que resume os termos de referências do projeto, que é disponibilizado no site da Fairtrade International (www. fairtrade.net) para dar oportunidade à todas as partes interessadas (incluindo o público) de opinar, comentar e fazer sugestões a respeito e, com base nestes comentários podem ocorrer modificações antes de se tornar a versão final do projeto (KRATZ, 2016, p. 2).

Terminada a fase do projeto um gerente de projetos designado de Padrões e Preços realiza junto uma pesquisa, na qual pode envolver as partes interessadas conforme necessidade para desenvolver um esboço da redação padrão (KRATZ, 2016, p. 2).

Elaborado o esboço do padrão, o mesmo é enviado para as partes interessadas identificadas para uma manifestação formal, incluindo produtores, redes de produtores, fornecedores, varejistas, outras unidades dentro da Fairtrade International, FLOCERT e Organizações de Comércio Justo nacionais. Este esboço também é publicado no sítio do Fairtrade International na rede Internet para consulta pública durante o prazo que varia entre 30 dias para projetos menores e 60 dias para grandes projetos, com uma segunda rodada de pelo menos 30 dias para novos padrões, que podem ser reduzidos em caso de uma revisão urgente (KRATZ, 2016, p. 2).

Finalizadas as consultas públicas, os padrões passam por um Comitê de Critérios Fairtrade, que é formado pelas partes interessadas de produtores, comerciantes, organizações nacionais de Comércio Justo e especialistas externos, sendo que decisões menores também podem ser delegadas ao Diretor de Padrões e Preços (KRATZ, 2016, p. 2).

Todas as normas são revisadas pelo menos a cada cinco anos, sendo que as partes interessadas podem reclamar contra a configuração de um critério (Fairtrade Standard) seguindo os Procedimentos Operacionais Padrão para tanto (KRATZ, 2016, p. 2).

Como se pode verificar, atualmente o próprio sistema de formação de critérios oportuniza uma discussão pública e pulverizada, com abertura de espaço para diversos atores, seguimentos e vieses de interesses, sendo que a definição final deste processo é centralizada em um comitê formado pelas autoridades que representam todos os stakeholders.

Nota-se uma preocupação com a participação aberta e ampla dos diversos atores do 
sistema do Comércio Justo, inclusive, do público em geral, por meio de plataformas virtuais com amplitude de acesso Global, revelando claramente a adoção de uma forma de regramento altamente pulverizada, mas que centraliza toda dinâmica no âmbito da FLO e WFTO.

Pôde-se observar, ainda, no processo de construção da RPT no Fair Trade, não apenas uma intenção de coordenar e unificar os conceitos e atividades no campo, mas também de monopolizar a atuação regulatória privada, por parte da FLO e da WFTO, para se tornarem instituições focais no tema. Essa conclusão é sugerida pela elaboração do Quadro de Princípios sobre o Fair Trade e do Glossário do Fair Trade, bem como pela atuação em áreas distintas de certificação das duas grandes organizações: a FLO certifica produtos de Fair Trade, enquanto que a WFTO cuida das organizações do movimento. Parece haver, desta forma, uma tentativa de evitar a criação de competição na formulação das regras de certificação do Fair Trade (PARK, 2015, p. 79).

Neste caminho desafiador do desenvolvimento de regramentos embuídos do propósito de viabilização e crescimento do Comércio Justo na ressignificação de práticas frente ao mainstream, inúmeros elementos relacionais e seus desdobramentos surgem nas mais variadas formas, causando um desequilíbrio de interesses nas mais variadas dimensões, como no caso citado, acerca do controle destas ações de regulação à margem do sistema jurídico tradicional do Estado.

\section{REGIMES JURÍDICOS PRIVADOS E A GLOBALIZAÇÃO}

O mercado tradicional não se destina a resolver questões sociais, pelo contrário, busca de forma incessante a maximização de lucros. A disputa de poder pelo lucro, entre atores que detém o capital em face do produtor - elo mais fraco da rede nas relações de troca - mantém a população pobre isolada por um cinturão que lhes veda o acesso ao crédito, às oportunidades e ao direito de empreender e viverem por si mesmas (YUNUS, 2008).

Esse processo ocorre porque o sistema jurídico tradicional que regulamenta as relações de troca não alcançam as vulnerabilidades a que estão expostas os pequenos cafeicultores de economia familiar. Esse modelo promove uma equação de que quanto menor o desenvolvimento dos países, menores são os benefícios da globalização, com potencial retrocesso em questões sociais e ambientais e, no âmbito empresarial o modelo tradicional também exclui as empresas de pequeno/médio porte, muito embora sejam empregadoras de parcela significativa de mão-deobra mundial. O Livre comércio parte da premissa de que os países são homogêneos e os produtos devem ter o mesmo nível de tarifas, sendo objetivo das nações, alcançarem o mesmo nível de desenvolvimento, porém, na prática existem disparidades que se reforçam, sendo que países em desenvolvimento se especializam na produção e exportação de bens intensivos em mão-de-obra (agrícolas/primários) (SCHIMIT, 2011, p. 17).

Isto porque a legislação tradicional regulamenta o que se denomina universo das trocas instantâneas (spot) do comércio convencional, cujos negócios se resumem na troca de bens e valores, mutuamente aceitos e assim equalizados pela oportunidade e interesse momentâneo, onde os critérios de fixação de preços e formas de pagamento estão distantes das circunstâncias, muitas vezes peculiares, de produção do produto. A grande diferença do sistema de Comércio Justo é que não se regulamenta uma relação de mercado spot, mas um contrato cujo vínculo de longo prazo entre as partes, baseado na confiança (MOREIRA et al., 2011, p. 345), constitui um projeto amplo e pulverizado de expectativas e atritos que assim se estabilizam, pois, a análise de redes revela distribuições desiguais de poder nas relações entre produtores, consumidores e trabalhadores, em redes descentralizadas, transnacionais e globais (MCEWAN; BEK, 2009).

Com isso, compreender a função que o contrato assume no processo de ligação destes atores em rede se faz pertinente, pois, propõe uma lógica negocial diferente do objetivo do lucro puro e simples, modelo supra descrito em que se verifica uma falha dos pressupostos que legitimam a proposta do liberalismo, falha esta que vem causando concentração de riqueza em mão de $1 \%$ da 
população mundial e pobreza nas regiões mais distantes do globo, degradação do meio ambiente e exploração de vidas, em afronta aos princípios da bioética global.

Com efeito, no sistema neo-liberal a racionalidade econômica permeia e domina todas as outras racionalidades científicas, culturais, artísticas, etc. pois, a maximização do lucro como objetivo principal gera desequilíbrios e assimetrias que se traduzem em perdas nas relações de troca, onde invariavelmente são suportadas pela parte mais frágil e mais suscetível da cadeia de valor (TEUBNER, 2005, p. 279).

Esse fenômeno é percebido em toda sociedade, na medida em que é o dinheiro e não mais o poder ou a política que vão instrumentalizar os saberes, os propósitos e empreendimentos, as funções tidas como públicas devido à importância social que as pertence, pois, estão privatizadas e se expressam na exploração comercial de setores como a pesquisa, saúde, educação, segurança, infra- estrutura, etc... e, esta lógica se replica no âmbito privado também, como na arte, na música, nos esportes. Enfim, a racionalidade econômica estruturada na sociedade global causa os desentendimentos mercadológicos, mitiga o verdadeiro sentido e importância dos saberes (TEUBNER, 2005, p. 293), o que implica em uma abordagem sociológica jurídica acerca desta estrutura jurídica em estudo.

Num mundo instantâneo e dinâmico, o direito estático e rígido não mais suporta as instabilidades que a volatilidade das relações humanas se realizam de forma exponencial, sem limites fronteiriços. A sociedade globalizada na pós-modernidade vê a economia, a ciência, a tecnologia, os meios de comunicação em massa, a medicina, a educação e o transporte se desenvolverem espontaneamente e, com isso, uma carência enorme de normas surge pela incapacidade das instituições estatais nacionais ou internacionais acompanharem estas demandas, fazendo com que estes próprios setores o façam por si mesmos, num processo de criação de normas paralelo e marginal às tradicionais fontes do direito. O direito oficial dos Estados, cujo sistema está estruturado na função cogente e vinculativa de normas gerais, aos poucos foi deixando de atender estas demandas e abrindo lacunas para novos sistemas jurídicos (TEUBNER, 2005, p. 108-109).

Com isso, o contrato surge como um instrumento dinâmico, voltado a objetivos amplamente diversificados e complexos, pelos mais variados interesses que o conformam. A proposta discursiva de um projeto contratual promove com seu cerne discursivo-comunicativo uma abordagem condizente com as diversas atividades e interesses colidentes que envolvem a rede. Porém, o contrato não é mais visto como um instrumento estático e previsível, mas como palco Teubner (2005) de uma relação jurídica contratual conflituosa entre discursos, jogos linguísticos, textualidades e projetos colidentes.

Nesse sentido, o fenômeno dos regimes privados globais à margem do direito tradicional se desenvolve e, ao mesmo tempo que acoplado às legislações nacionais e tratados internacionais, se legitima com uma auto-produção normativa que não dialoga primeiramente com o direcionamento político de processos sociais, mas sim, priorizando as suas necessidades originárias de estabilização e solução de conflitos, um projeto sistêmico de auto criação que envolve inúmeras expectativas entre seus atores, que atuam na formação destes regimes privados, na periferia e margem do direito estatal, e para além das fronteiras do direito com outros subsistemas globais, onde a tônica do novo direito global é ser um direito periférico, espontâneo e gerado pela sociedade (TEUBNER, 2005, p. 109-110).

Esse fenômeno é claramente visível pela a criação de fóruns e organizações guarda-chuva, a articulação das ONGs, sobretudo no eixo do FINE (FLO, IFAT, hoje WFTO, NEWS! e EFTA), para influenciar a criação de regras em âmbito internacional, bem como para dar maior visibilidade legislativa ao movimento do Comércio Justo, estabilizando um regime regulatório privado cuja construção ocorreu inicialmente de forma difusa e local, e que parece hoje se concentrar em duas principais organizações: a FLO na elaboração de padrões de certificação de produtos Fair Trade e a WFTO na certificação de organizações que atuam no Fair Trade. 
E isso em razão da ausência de formulação legislativa por parte da União Europeia, local de principal atividade de advocacia realizado pelo setor privado para a cooperação da regulação sobre Fair Trade, demonstrando que o processo de construção do regime jurídico privado ocorreu de maneira independente à atividade regulatória estatal sobre o tema (PARK, 2015, p. 78), corroborando o pensamento supra exposto do jus sociólogo alemão. "Os novos regimes privados surgem, justamente, não na base de coordenação informal de comportamento num processo gradativo de interações recursivas, mas em razão de serem positivados em processos decisórios organizados nos subsistemas sociais." (TEUBNER, 2005, p. 112).

Estes regimes jurídicos são coordenados pelo projeto discursivo que o originou e, sendo assim, na pós-modernidade global o direito tende a fragmentar-se em razão destes propósitos, onde as relações irão se orientar por seus "clãs" e "tribos" - que se alinharão por estes propósitos - de modo que para Teubner (2005, p. 114) a ordem jurídica mundial deve abdicar da força inerente à sanção organizada e da definição autêntica de infrações do direito por regras conhecidas, mas ao mesmo tempo, observar até onde estes regimes estão envolvidos na dialética de seu caráter apolítico e de sua repolitização (TEUBNER, 2005, p. 277).

Ambas as tendências decorrentes da globalização jurídica e a privatização, levam à necessidade de repensar a normatização de governos transnacionais privados e a criação normativa privada. Os regimes jurídicos privados representam um direito genuíno, que não pode ser mais ocultado, pois, articulam e cumprem tarefas legislativas, administrativas, regulatórias e de soluções de conflitos do direito clássico em novas formas e em novos contextos, numa sociedade civil dinâmica e pluralista de subsistemas sociais globais, que se impõem autonomamente aos mercados mundiais e aos cenários políticos globais, e isso por sua racionalidade autônoma presente no interesse do grupo, de sua focalização organizacional (TEUBNER, 2005, p. 120).

\section{OS REGIMES JURÍDICOS PRIVADOS COMO INSTRUMENTO DE DESENVOL- VIMENTO}

O jus sociólogo alemão Gunther Teubner (2005, p. 279) explica que a fragmentação do mundo social em várias dinâmicas de racionalidade significa que um mesmo contrato surte em, no mínimo, três projetos e nos respetivos mundos sociais: 1. como acordo produtivo; 2 . como transação econômica; e 3. como relação de obrigações jurídicas. Primeiro, o contrato se reconstrói como um projeto "produtivo" em um dos muitos mundos sociais - produção, distribuição ou serviços em tecnologia, ciência, medicina, jornalismo, esporte, turismo, educação ou arte. Segundo, o mesmo contrato se reconstrói no mundo econômico como projeto empreendedor, como transação monetária rentável em condições de mercado mais ou menos competitivas. Em terceiro lugar, o contrato é finalmente reconstruído, no mundo do direito, como um projeto jurídico, como um compromisso que vincula por determinado tempo e como uma obrigação que gera normas. E ainda, complementa, que cada um desses projetos faz parte de uma dinâmica autônoma de acontecimentos cheios de atalhos - sistema produtivo, sistema econômico, sistema jurídico - que a forçam andar em direções diferentes.

No entanto, para o autor o termo contrato relacional frente à realidade supra conjecturada de hoje deve ser entendido de forma realista, ou seja, no sentido de ser uma relação cheia de conflitos entre discursos, jogos linguísticos, sistemas, textualidades de projetos colidentes (TEUBNER, 2005, p. 281), porque para o autor, o contrato vincula não a vontade autêntica dos homens, mas os interesses, construídos de forma totalmente social, de assim chamados parceiros contratuais que apenas existem como artefatos semânticos, como textos, como produtos de um discurso, agentes interesses fingidos, transportam desejos subjetivos para os textos de seus jogos linguísticos altamente artificiais, não a intersubjetividade, mas intertextualidade é o significado 
da relação contratual, na medida em que ela não interliga estados da consciência subjetivos, mas interesses construídos de forma social (TEUBNER, 2005, p. 282).

No centro do interesse encontra-se, então, não a dimensão interpessoal, mas a dimensão prática da relação contratual - a lógica da permuta é sobrescrita por uma lógica de projeto, onde o dualismo das partes contratuais é substituído pelo dualismo de textos, pois, o texto discursivo originário e sua transformação em um novo texto por meio de promessas e cumprimentos contratuais, vinculando não apenas a vontade de ambos os parceiros, mas sua conversação, ele vincula o sistema social que se edifica entre eles, o que é decisivo por essa perspectiva, já que a atenção da obrigação das partes para o papel constitutivo da celebração do contrato é desviada para a construção de um sistema social autônomo, na medida em que transforma expectativas latentes em obrigações reais, e o que eram meras projeções agora são vínculos operativos. É assim, portanto, que aparece a verdadeira dinâmica social do contrato; ele não obriga apenas dois agentes à permuta de seus recursos, mas gera estruturas de um sistema social que força a uma determinada direção, a saber, ao cumprimento do objeto do contrato. Esse vínculo se refere, novamente, em primeiro lugar ao projeto do discurso especial produtivo sobre o qual o contrato surte efeitos (TEUBNER, 2005, p. 283).

Este ambiente volta à atenção das obrigações para uma nova forma de agir e pensar, de modo a pertencer a este sistema social, em razão e função das expectativas latentes. As obrigações e ações reais concretizam a transformação social pelo cumprimento do contrato, pois, ele não obriga mais apenas comprador e vendedor na troca de seus recursos, mas agora força a participação unida dos agentes, em um novo patamar de consciência e responsabilidade, dentro da nova estrutura de um sistema social, no interesse comum de obter o cumprimento do objeto do contrato. Esse vínculo se refere, novamente, em primeiro lugar ao projeto do discurso especial produtivo sobre o qual o contrato surte efeitos.

Cria-se, por meio deste contrato relacional, um universo, um mundo paralelo de ações e propósitos que efetivamente, pretende envolver e beneficiar os atores mas, também, terceiros não envolvidos, as gerações futuras, o meio ambiente, a fauna, a flora, a biosfera de uma maneira mais ampla, enfim, em compasso com os objetivos bioéticos outrora invocados que são, na verdade, espectros da racionalidade além da econômica, pertencentes às racionalidades próprias dos saberes científicos, culturais e transcendentais envolvidos.

Então, a execução do contrato significa, em essência, a tradução mútua e bem-sucedida de projetos discursivos. Ele traduz permanentemente informações do projeto produtivo para o projeto econômico e jurídico e vice-versa (TEUBNER, 2005, p. 284). Porém, para Teubner (2005, p. 285), a tradução, o entendimento harmônico interdiscursivo é impossível, e complementa que entre discursos, a transmissão de sentido é impossível, mas ao mesmo tempo necessária. $\mathrm{O}$ autor, entrementes, apresenta uma explicação no sentido de que a saída deste paradoxo é encontrada no que denomina por mal-entendidos produtivos. Um discurso só pode reconstruir o sentido de um outro com seus próprios termos, em seu próprio contexto, mas, no entanto, ele pode, simplesmente, tornar proveitoso o material de sentido de outros discursos, como irritação externa, para criar internamente algo novo. Nesse sentido a tradução contratual compreende mal, fundamentalmente, o sentido do acordo no outro discurso, e exatamente por meio disso gera valor agregado. Através da tradução contratual cada uma dessas línguas é capaz de entender mal cada uma das outras de forma reconstrutiva e tirar proveito desse mal-entendido de vez em quando.

$\mathrm{O}$ exemplo do autor acerca do mal-entendido produtivo refere-se à um contrato de patrocínio, onde uma empresa patrocinadora, renomada fábrica de veículos de luxo, contrata uma artista para composição de uma Ópera. $\mathrm{O}$ artista não possui nada efetivamente a oferecer ao patrocinador, porém, compõem sua ópera conforme a dinâmica interna de seu discurso artístico, que decide sozinho - e sem consideração do preço de mercado e popularidade - sobre o valor artístico, porém, o capital investido é traduzido em energia material, temporal e pessoal artística 
na construção do projeto estético. Nada garante o sucesso dessa empreita, porém 'o mal-entendido contratual possibilita que, no mundo das transações econômicas, a ópera seja entendida como algo que melhora a imagem da empresa e aumenta assim, a longo prazo, sua rentabilidade. E vice-versa, as intenções profanas de objetivos de maximização do lucro são mal-entendidas no discurso artístico de forma produtiva, inexiste garantia de que tal mal-entendido será produtivo (TEUBNER, 2005, p. 286).

Assim, portanto, o contrato permite que diferentes racionalidades sociais e linguagens de ciências diferentes possam atuar de forma produtiva, mas sempre diante da existência de um propósito específico, cujos sentidos se justifiquem na linguagem própria de cada uma delas.

Assim, é que regras normativas geradas pelo regimes jurídicos privados que são mal entendidas na economia como fatores de custo, vinculam planejamento, investimento econômico a um prazo mais longo e abrem novas possibilidades de transações de alto risco. O mesmo ocorre com as regras jurídicas que são produtivamente mal entendidas como um fortalecimento de padrões profissionais futuros, agregando o valor da dinâmica jurídica para as esferas econômica e produtiva no vínculo temporal duradouro que amplia o horizonte para cadeias de acontecimentos produtivos e econômicos (TEUBNER, 2005, p. 287).

O que se verifica nesta nova tendência de um sistema social é que tentam impor sua versão da tradução a outros mundos de sentidos. O direito tradicional, cujos princípios até agora tinham atenção voltada para a liberdade contratual e a proteção da liberdade de decisão individual no mercado contra fraude, engano e especialmente contra a intervenção política excessiva, a nova atenção agora está ligada à proteção da dinâmica da tradução contratual contra o próprio mercado, quando o discurso econômico começa a monopolizar o direito da tradução interdiscursiva e impor traduções econômicas a outros discursos. A liberdade da reconstrução discursiva é, portanto, o mecanismo que se volta contra o mecanismo da racionalidade econômica, contra o projeto de uma construção econômica do mundo (TEUBNER, 2005, p. 289).

No entanto, essa transformação do direito privado não ocorre de forma isolada de seus ambientes sociais, o direito privado recebe suas informações sobre o resto da sociedade quase automaticamente e quase exclusivamente por meio do cálculo custo-benefício do discurso econômico. Todos os outros discursos da sociedade, sejam estes da ciência, da educação, da tecnologia, da arte ou da medicina, devem passar por esse filtro. Eles são, primeiramente, traduzidos para o mundo do cálculo econômico, para que então essa tradução seja apresentada ao direito para a solução do conflito (TEUBNER, 2005, p. 290).

Essa contextualização é importante para demonstrar a urgência com que o direito privado deve estabelecer contato com os outros subsistemas racionais, o que de certa forma já ocorre quando cláusulas gerais de bons costumes, critérios não-econômicos, funções sociais, boa-fé, que são invocados para compensar as assimetrias geradas pelos critérios econômicos constantes dessa racionalidade dominante. Porém, estas correções marginais não se propõem a reequilibrar a simetria dentro do triângulo discursivo do contrato de maneira ampla e estão distantes por serem aplicados nas relações spot.

Assim, entender o contrato como tradução do jogo linguístico, aqui tomando o centro de estudo o discurso conceitual que envolve o Comércio Justo, em que a sua autonomia não está no indivíduo mas, na coletividade que o compartilha, pressupõe a transferência dessa autonomia ao propósito de interesses comuns contidos no regime discursivo, não de uma forma abstrata, mas de forma concreta tamanha a sua força de adesão social, no caso, em amplitude Global. Nesse sentido, questiona-se se o efeito a terceiros de direitos fundamentais no âmbito do direito privado deve ser alterado, passando de uma proteção meramente relacionada ao indivíduo para a proteção de instituições, redes, sistemas e discursos impessoais diante das ameaças no setor privado. Um correlato normativo para o contrato como tradução de jogos linguísticos seria a ampliação do entendimento dos direitos fundamentais relacionados com o sistema ao contexto dos private 
governance regimes (TEUBNER, 2005, p. 291).

Um conceito discursivo dos direitos fundamentais deve voltar-se contra qualquer sistema social que apresente tendências totalitárias, entendendo que direitos de discurso, podem formar o fundamento de uma reconstrução do direito privado contemporâneo cuja tarefa principal seja a proteção das muitas autonomias não apenas diante do Estado repressivo, mas também especialmente contra as tendências expansivas da tecnologia, da ciência, das mídias de publicação e do mercado. As esferas de liberdade e dignidade individual, a auto-realização do indivíduo, os discursos de pesquisa, arte, educação, comunicação de mídia, a esfera da própria política devem ser protegidos contra a monopolização da tradução por discursos expansivos econômicos e técnicos (TEUBNER, 2005, p. 292).

\section{CONSIDERAÇÕES FINAIS}

A proposta contida no discurso do Comércio Justo busca claramente atender demandas que não são alcançadas pela atuação dos Estados, cujo projeto visa construir novas formas de relações obrigacionais, cujo modelo coaduna com a visão do jus sociólogo Gunther Teubner cujos aportes foram apresentados neste trabalho.

Assim, o regime jurídico privado do Comércio Justo é típico sistema global de regulação contratual, cujos valores e princípios foram atualizados e nutridos pelas manifestações e demandas globais de inúmeros subsistemas, como a preservação do meio ambiente, respeito à dignidade humana, proteção e segurança do trabalho, respeito à igualdade de gêneros, vedação do trabalho escravo e ao trabalho infantil.

A forma moderna que se estruturam estas relações jurídicas se verifica na coordenação especializada e plural, pulverizada no interior de subsistemas, de forma ampla e democrática, voltada para o aperfeiçoamento constante e rápida adequação às irritações e demandas externas, sempre atentas ao propósito que as legitima, constantes no discurso conceitual do Comércio Justo.

A despeito da propalada abertura do processo de criação de padrões, a centralidade e o monopólio na condução destes faz com que seja inevitável o surgimento de uma linha muito tênue entre os interesses mercadológicos e os princípios do movimento, notadamente pelo fato de que as afirmações discursivas do Comércio Justo traduzem a natureza contra-hegemônica com que suas regras, práticas e políticas foram e são elaboradas, no desafio de se situar em um mercado altamente competitivo e dominado por grandes oligopólios. Assim, é evidente que não se trata de um movimento isento, pelo contrário, sua gênese é a politização de seus valores e princípios no mercado.

Há na formação e execução do projeto contratual uma reunião de ações articuladas para alcançar o propósito do movimento, composta pelos mais variados áreas do conhecimento e expertises, que estão reunidos e são autônomos dentro do mesmo sistema de obrigações.

Este modelo contratual difere significativamente da relação entre dois indivíduos que trocam seus bens e recursos para fins de satisfação mútua. Trata-se, portanto, de um contrato relacional em que não há uma estabilidade, como um mar de águas calmas e tranqüilas, pelo contrário, existem diferentes lógicas próprias que se debatem, se articulam e se estressam, numa reunião de obrigações que naturalmente são contraditórias pelas diferentes lógicas que as fundamentam.

Relacional não significa, portanto, apenas colocar contrato em relação às exigências de cooperação, adaptação e boa-fé, mas também às exigências, que muitas vezes se contradizem, de vários âmbitos de atuação que são ligados por meio da instituição do contrato. Isto não significa a perda da autonomia individual, pelo contrário, a mantém intacta em uma dimensão mais ampla que a outrora existente no ambiente negocial, pois, o participante da rede - seja produtor, industrial, transportador, etc - pode entrar e sair do sistema no momento que desejar, existindo mecanismos 
próprios para desfazimentos de contratos, inclusive.

Mais do que isso, o sistema legitima o partícipe quando todas as ações, regras e padrões são definidos pelos mesmos, de forma democrática, desde os seus locais até o centro coordenador, dentre os mais diversos e universais interesses que se relacionam na rede.

Este raciocínio dentro do universo deste trabalho do Comércio Justo pode ser entendido no sentido de que a lógica econômica cede o espaço necessário para o funcionamento de outras lógicas alicerçadas na racionalidade de outros conhecimentos, o que significa aumento de recursos investidos, como energia de trabalho, recursos humanos, capital, dentre outros.

Compreende-se, portanto, que isso faz sentido pela possibilidade de todo o capital aqui toda estrutura operacional envolvida de forma autônoma no projeto contratual - vir a ser recompensado ao final, pelo alcance do objetivo no produto final, imbuído dos valores tangíveis e intangíveis constantes do objeto, do discurso do contrato que ligam todos os atores pelo malentendido produtivo, envolvendo, inclusive, o consumidor final predileto.

O fenômeno da globalização ascendeu uma autonomia aos setores sociais mundiais que tende e pode institucionalizar uma constituição dual do direito privado. No caso do discurso do Comércio Justo e as reivindicações e propósitos da bioética, vislumbra-se um universo de estruturação jurídica dos regimes jurídicos privados como instrumento dinâmico que viabiliza ações potencialmente transformadoras, de forma autônoma altamente mutante, versátil e democrática.

\section{REFERÊNCIAS}

ABRAHAMSEN, Rita. The power of partnerships in global governance, third word quartely. Third Word Quartely, London, v. 25, n. 8, p. 1453-1467, 2004. DOI: 10.1080 / 0143659042000308465

BARONE, Marcela. Cafés especiais e salto de escala: análise do circuito espacial produtivo e dos círculos de cooperação dos cafés especiais no Sul de Minas Gerais. Rio Claro - SP, 2017. Dissertação (Mestrado em Geografia) - Universidade Estadual Paulista Júlio de Mesquita Filho, Rio Claro, 2017.

BULGARELLI, Waldirio. Contratos Mercantis. Ed. Atlas. São Paulo. 14ª Edição. 2001. P. $63 / 64$.

CASTALDO, Sandro; FRANCESCO, Perrini; MISANI; Nicola; TENCATI, Antonio. The missing link betwenn corporate social responsability and consumer trust: the case of Fair Trade products. Journal of Business Ethics, Dordrecht, v. 4, p. 1-15, 2009. CLAC - COORDINADORA LATINOAMERICANA Y DEL CARIBE DE PEQUEÑOS PRODUCTORES Y TRABAJADORES DE COMERCIO JUSTO. ¿Qué es CLAC? [2019]. Disponível em: http://clac-comerciojusto.org/clac/presentacion/quienes-somos/. Acesso em: 12 jul. 2019.

DECLARAÇÃO final. In: II FÓRUM MUNDIAL DE PRODUTORES DE CAFÉ, 2., 2019, Campinas, 2019. Disponível em: http://www.cncafe.com.br/site/interna.php?id=14913. Acesso em: 15 jul. 2019.

DINIZ, Maria Helena. Curso de direito civil brasileiro: teoria das obrigações contratuais e extracontratuais. 19. ed. São Paulo: Saraiva, 2003.

FLO - FAIR TRADE INTERNACIONAL. Definition of Fair Trade. Brussels: FLO, 2018. Disponível em: https://fairtrade-advocacy.org/definition-of-fair-trade/ . Acesso em: 14 maio 2019. 
FLO - FAIR TRADE INTERNACIONAL. Setting the Standards, 2019. Disponível em: https:// www.fairtrade.net/standards/setting-the-standards.html. Acesso em 14 mai. 2019.

FLO - FAIR TRADE INTERNACIONAL. Standards, 2019. Disponível em: https://www.fairtrade.net/standards.html. Acesso em 14 mai. 2019.

GARRAFA, Volnei. Da bioética de princípios a uma bioética interventiva: simpósio. Revista Bioética, Brasília, v. 13, n. 1, 2005.

GREWAL, David Singh. Ethics and International Affairs. 2008. Disponível em: http://www. seeta.com/documents/David\%20Grewal\%20July2008.pdf. Acesso em: 26 mar. 2021.

KRATZ, Andreas. SOP Public Development of Fairtrade Standards - Short Version. Fairtrade Internacional. 2016. Disponível em: https:/www.fairtrade.net/fileadmin/user_upload/ content/2009/standards/SOP_short_Development_of_Fairtrade_Standards.pdf Acesso em: 20 mar. 2019.

MASCARENHAS, Gilberto Carlos Cerqueira. O movimento do comércio justo e solidário no brasil: entre a solidariedade e o mercado. 2007. 387 f. Tese (Doutorado em Ciências Sociais em Desenvolvimento, Agricultura e Sociedade) - Instituto de Ciências Humanas e Sociais, Universidade Federal Rural do Rio de Janeiro, Seropédica, 2007.

MCEWAN, Chery; BEK, David. The political economy of alternative trade: social and environmental certification in the south african wine industry. Journal of Rural Studies, v. 25, n. 3, p. 255-266, 2009.

MOREIRA, C. F.; FERNANDES, E. A. de N.; VIAN, C. E. de F. CARACTERÍSTICAS DA CERTIFICAÇÃO NA CAFEICULTURA BRASILEIRA. Organizações Rurais \&amp; Agroindustriais, [S. 1.], v. 13, n. 3, 2012. Disponível em: http://www.revista.dae.ufla.br/index. php/ora/article/view/429. Acesso em 28.11.2017.

PARK, Christine Seung Hee. Processos jurídicos transnacionais estatais: o fair trade e a construção do sistema de comércio justo e solidário no Brasil. Coleções FGV DIREITO SP - Dissertações, Mestrado em Direito. 2015. São Paulo. URI: http://hdl.handle.net/10438/13721. Acesso em 15 abr. 2019.

PEDINI, Sérgio; MACHADO, Rosa T. Moreira. Fair Trade: possibilidades de empoderamento de cafeicultores familiares no sul de Minas Gerais. Estudos Sociedade e Agricultura. Lavras, v. 22, n. 2, p. 457-481, out 2014. Disponível em: https://revistaesa.com/ojs/index.php/esa/article/ view/392 Acesso em 10 fev. 2018.

PEREIRA, Caio Mário da Silva. Instituições de direito civil: teoria geral de obrigações. Rio de Janeiro: Forense, 2004. v. 3.

PESSINI, Léo. As origens da bioética: do credo bioético de Potter ao imperativo bioético de Fritz Jahr. Revista Bioética, Brasília, v. 21, n. 1, 2013. Disponível em: http://www.scielo.br/pdf/ bioet/v21n1/a02v21n1. Acesso em: 8 jul. 2019.

RIOS, Kimberly; FINKELSTEIN, Stacey; LANDA, Jennifer. Is there a "fair" in fair-trade? social dominance orientation influences perceptions of and preferences for fair-trade products. 
Springer Science. Dordrecht: Business Mídia, 2014.

RUFINO, José Luis dos Santos; SILVEIRA, Victor de Souza; RIBEIRO JUNIOR, Adelmo Cardoso. Introdução e metodologia de estudo. In: VILELA, Pierre Santos; RUFINO, José Luis dos Santos. Caracterização da cafeicultura de montanha de Minas Gerais. Belo Horizonte: Inaes, 2010. Cap. 1.

SCHIMIT, Valentina Gomes Haensel. As Dimensões da Sustentabilidade nas Relações de Poder: O Comércio Justo no Setor Alimentício Brasileiro. Rio de Janeiro. Tese (Escola Brasileira de Administração Pública e de Empresas) - Fundação Getúlio Vargas, 2011.

SCHNEIDER, Johann. Pesquisa mundial de comércio justo: parte 1. Brasília: SEBRAE, 2012.

SCHRAMM, Fermin Roland. Bioética da Proteção: ferramenta válida para enfrentar problemas morais na era da globalização. Revista Bioética, Brasília, v. 16, n. 1, p. 11-23, 2008. Disponível em: https://www.redalyc.org/pdf/3615/361533250002.pdf . Acesso em: 19 maio 2019.

SCHRAMM, Fermin Roland. Uma breve genealogia da bioética em companhia de Van Rensselaer Potter. Revista Bioethikos, v. 5, n. 3, p. 302-308, jul./set. 2011. Disponível em: https://www.arca.fiocruz.br/handle/icict/25680 Acesso em: 08 jul. 2019.

TEUBNER, Gunther. Direito, Sistema e Policontexturalidade. Piracicaba - SP: Unimep, 2005.

UNESCO. ORGANIZAÇÃO DAS NAÇÕES UNIDAS para Educação, a Ciência e a Cultura. Declaração Universal sobre Bioética e Direitos Humanos. Lisboa: Unesco; 2005. Disponível em: https://unesdoc.unesco.org/ark:/48223/pf0000146180_por Acesso 20 nov. 2018.

VENOSA, Silvio de Salvo. Direito civil. São Paulo: Atlas, 2003. v. 2

WILKINSON, John. Fair Trade: dynamics and dilemas of a Market oriented global social movement. . Journal of Consumer Policy, v. 30, p. 219-239, 2007. Disponível em: <https:// s3.amazonaws.com/academia.edu.documents/45891692/s10603-007-9036-320160523-20299qk452.pdf?AWSAccessKeyId=AKIAIWOWYYGZ2Y53UL3A\&Expires=1532044150\&Signa ture $=$ ov5UqSRVUWc19cvK9VSYZnNN4bI\%3D\&response-content-disposition=inline $\% 3 \mathrm{~B} \% 20$ filename\%3DFair_Trade_Dynamic_and_Dilemmas_of_a_Mar.pdf >.Acesso em: 14 mai. 2019.

WORD BANK. Quase Metade do Mundo Vive com Menos de USD \$5.50 por Dia. Disponível em: https://www.worldbank.org/pt/news/press-release/2018/10/17/nearly-half-the-world-liveson-less-than-550-a-day-brazilian-portuguese. Acesso em: 10.02.2019.

YUNUS, Muhammad. Um mundo sem Pobreza: a empresa social e o futuro do capitalismo. São Paulo: Ática, 2008.

Como citar: BAGANHA, José Ricardo dos Santos; SIMIONI, Rafael Lazzarotto. Comércio justo e bioética: a legitimidade de regimes jurídicos privados. Scientia Iuris, Londrina, v. 25, n. 2, p. 168-186, jul. 2021. DOI: 10.5433/21788189.2021v25n2p168. ISSN: 2178-8189.

Recebido em 27/03/2021

Aprovado em 14/07/2021 